\title{
La argumentación en la esfera escolar: análisis pragmalingüístico
}

\author{
The argumentation in the school sphere: pragma linguistic \\ analysis
}

\author{
María Elena Villanueva Chaucas \\ Universidad Nacional Mayor de San Marcos, Lima, Perú \\ mavich2012@gmail.com
}

\begin{abstract}
Resumen
El presente estudio tiene como objetivo caracterizar la argumentación escolar bajo el enfoque pragmalingüístico a partir del análisis de textos argumentativos escritos por un grupo de adolescentes (edad promedio 16) que se encuentra en el último grado de secundaria de Educación Básica Regular. En el marco de esta investigación, se explican los componentes pragmáticos y lingüísticos, tales como fuerza ilocucionaria del acto argumentativo, el soporte retórico y la orientación argumentativa. La metodología de trabajo se delinea como una investigación cualitativa con orientación descriptiva, puesto que se muestra la configuración de la argumentación escolar. Los resultados evidencian el uso recurrente de reservas, declarativos de uso y la reiteración del punto de vista en la producción de los argumentos. Por otro lado, la estructura argumentativa que diseñan los estudiantes en todos sus argumentos es, preferentemente, arracimada. Asimismo, se halló un mayor uso de conectores argumentativos coorientados, en relación con los antiorientados, sin dejar de lado los reformuladores y operadores argumentativos. En cuanto al soporte retórico, es frecuente el uso de técnicas argumentativas como el argumento pragmático y el de definición.
\end{abstract}

Palabras clave: Acto de habla, fuerza ilocucionaria del acto argumentativo, orientación argumentativa, soporte retórico, estructura argumentativa

\begin{abstract}
The present study aims to characterize the school argumentation under the pragma linguistic approach from the analysis of argumentative texts written by a group of adolescents (average age 16) in the last grade of secondary school of regular basic education. Within the framework of this investigation, the pragmatic and linguistic components are explained, such as the illocutionary force of the argumentative act, the rhetorical support and the argumentative orientation. Since the configuration of the school argumentation is shown, the research methodology is designed as a qualitative investigation with descriptive approach. The results show the recurrent use of reservations, declarations of use and reiteration of the point of view in the production of its arguments. On the other hand, the argumentative structure that students design in all their arguments is preferably clustered. Likewise, there was a greater use of co-oriented argumentative connectors, in relation to the anti-oriented ones without neglecting the re-formulators and argumentative operators. As for rhetorical support, the use of argumentative techniques such as pragmatic and definitional arguments is frequent.
\end{abstract}

Keywords: speech act, illocutionary force of the argumentative act, argumentative orientation, rhetorical support, argumentative structure.

Recibido: 29.06.19 Aceptado: 15.08.19 


\section{María Elena Villanueva Chaucas}

\section{Introducción}

Van Eemeren, Grootendorst y Snoeck (2006, p. 17) señalan que «la argumentación es una actividad verbal, social y racional que apunta a convencer a un crítico razonable de la aceptabilidad de un punto de vista adelantando una constelación de una o más proposiciones para justificar este punto de vista». El objetivo de argumentar es conducir al receptor a creer o a hacer aquello que el emisor pretende. Su práctica implica saber organizar las ideas y utilizar técnicas discursivas para que el público acepte las tesis propuestas de tal forma que las razones propuestas tengan el éxito deseado (Lo Cascio, 1998, p. 257).

La construcción de un discurso contiene recursos lingüísticos que movilizan los enunciados hacia la consecución del propósito comunicativo. Estos recursos no son exclusivos de los adultos, sino que se inicia desde la primera infancia (Migdalex, Rosemberg y Santibañez, 2014) y prosigue en hasta el desarrollo total de esta competencia.

Por ello, Camps y Dolz (1995) afirman que el domino de la argumentación debe ser un objetivo de enseñanza en los grados escolares de primaria y secundaria, por lo que la escuela debe brindar el espacio para que los estudiantes fortalezcan esta habilidad discursiva, y no solo sea aplicado en grados superiores. Es así que, al observar las prácticas argumentativas escritas de los escolares, en ese afán por hacer prevalecer su opinión, surgió el interés por indagar si existe una forma de descubrir la ruta que recorren sus argumentos, qué recursos lingüísticos utilizan con frecuencia para vincular dichos argumentos, cuáles son las estrategias argumentativas empleadas recurrentemente, cómo se evidencia el potencial justificatorio de sus argumentos y cómo estructuran su argumentación.

En virtud de ello, esta investigación intenta dar cuenta de las herramientas extralingüísticas y discursivas al que recurren con frecuencia los estudiantes, y se examinan los textos escritos a fin de descubrir las características pragmáticas y lingüísticas en las que basan la elaboración de su argumentación. Para ello, se toma como base diversos enfoques de la Teoría de la Argumentación (Perelman y Olbrechts-Tyteca, 1989; Toulmin, 2007; van Eemeren, Grootendorst y Snoeck, 2006); de la Teoría de los Actos de Habla (Austin, 1982; Searle, 1994; van Eemeren y Grootendorst, 2013); de los conectores argumentativos (Martín Zorraquino y Portolés, 1999; Domínguez, 2007) y la estructura argumentativa (Lo Cascio, 1998).

Es importante resaltar que esta investigación no ha estado exenta de dificultades y la principal la hemos encontramos al realizar la representación de la estructura argumentativa, dado que las propuestas teóricas-metodológicas de 
Toulmin (2007), van Eemeren, Grootendorst y Snoeck (2006) y Lo Cascio (1998) no consideran una situación argumentativa real, en el que los interlocutores no solo hacen uso de argumentos, sino de enunciados explicativos, especificativos, aclarativos o constantemente reformulan sus propios argumentos al punto de parecer contradictorios.

\section{Marco teórico}

La argumentación es un acto del discurso en el que encontramos diversos elementos pragmáticos, sintácticos, léxico-semánticos y discursivos, entre los que destacan los recursos retóricos, tipos de argumentos y falacias, deícticos y conectores (Bassols y Torrens, 1997, citado por García y Alarcón, 2015). Esta diversidad de aspectos involucrados en el acto argumentativo es la razón de hacer intervenir en nuestro estudio perspectivas distintas. Así, por un lado, retomamos algunas ideas de van Eemeren y Grootendorst (2013) en relación con los actos de habla, las técnicas argumentativas de Perelman y Olbrechts-Tyteca (1989) y la estructura argumentativa de van Eemeren, Grootendorst y Snoeck (2006) y Lo Cascio (1998).

\subsection{La argumentación como un acto de habla}

Austin (1982) determinó la presencia de tres niveles de actos de habla que se manifiestan durante las emisiones lingüísticas: a) el acto locucionario, la información que se transmite a través de los enunciados expresados; b) el acto ilocucionario, la intención o propósito del mensaje (prometer, sugerir, advertir, felicitar, afirmar, amenazar, etc.), y c) el acto perlocucionario, que corresponde a las consecuencias que produce en el destinatario el acto locucionario.

Años después, Searle (1994) continuó la concepción de Austin y se centró en el análisis de los actos ilocutivos. Aquí considera que el acto ilocucionario estaría conformado por un indicador proposicional, que muestra el contenido de la proposición, y un indicador de la fuerza ilocucionaria, muestra en qué sentido o con qué fuerza ilocutiva debe interpretarse la proposición, y, en suma, señala el acto ilocutivo que está realizando el hablante.

De acuerdo al valor de la fuerza ilocutiva los actos de habla se clasifican en 1) asertivos, constituidos por aquellos enunciados que expresan una creencia, más o menos firme, del hablante; 2) directivos, intentos del hablante de que el oyente realice alguna acción como invitar, sugerir, insistir, pedir, ordenar, aconsejar, 
suplicar y preguntar; 3) compromisivos, que comprometen en diversos grados al hablante con una actuación futura; 4) expresivos, que expresan un sentimiento o estado psicológico: dar las gracias, felicitar y disculparse, y 5) declarativos, que tienen la intención de modificar los estados de cosas en el mundo: renunciar, despedir, declarar, definir, clasificar y nombrar.

Esta clasificación de los actos de habla, no obstante, pasaba por alto a la argumentación, que a decir de van Eemeren y Grootendorst (2013) es un acto de habla. Dichos autores consideraron que la argumentación es un acto ilocutivo complejo compuesto por ilocuciones pertenecientes a los asertivos, los que mantienen una relación entre ellos, y que en conjunto conforman el acto de habla argumentativo que se produce a nivel textual. Este acto complejo de la argumentación presenta las siguientes características:

a. Los argumentos están formados por más de una oración. Al menos dos oraciones forman parte del argumento.

b. Los actos de habla poseen una fuerza ilocutiva que se expresa en cada enunciado (asertivos) y otra fuerza ilocutiva argumentativa a nivel textual.

c. Si aceptamos un acto de habla argumentativo, entonces este acto de habla establece una relación entre los actos habla elementales que lo conforman.

Por otra parte, en la argumentación escolar suele presentarse con mucha frecuencia enunciados que no son propiamente argumentos ni reglas generales, pero que esclarecen a un argumento, a una regla o una reserva, y que los citados autores conceptualizan como declarativos de uso (DU). Estos son actos de habla que ayudan a precisar, ampliar, explicar, definir o explicitar los argumentos, con el propósito de asegurar la comprensión mutua de los actos de habla que transmite el emisor hacia el receptor. Si bien los declarativos de uso (DU) se presentan como asertivos, los interlocutores deben ser capaces de distinguir entre un argumento a partir de su potencial justificatorio en relación a la opinión expresada y un declarativo de uso que se utiliza para incrementar la comprensión de la argumentación.

\subsection{El soporte retórico de la argumentación}

En su monumental libro, Perelman y Olbrechts-Tyteca (1998) clasifican los argumentos sobre la base de dos procedimientos: de enlace y disociación. El primero consiste en trasladar a la conclusión la adhesión que poseen las premisas. De él

$70 \quad$ Lengua \& Sociedad, vol. 18, n. ${ }^{\circ}$ 1, Lima, enero-junio de 2019 
emergen $a$ ) los argumentos cuasilógicos, $b$ ) los basados en la estructura de lo real y c) los que fundamentan la estructura de lo real; sobre la disociación sostienen que esta «trata de separar elementos que, el lenguaje o una tradición reconocida, han ligado previamente uno a otro» (Perelman y Olbrechts-Tyteca, 1998, p. 76).

Los argumentos cuasilógicos tienen una estructura similar a los utilizados en el razonamiento lógico-formal (Perelman y Olbrechts-Tyteca, 1998, p. 304). Destacan entre este tipo de argumentos: $a$ ) el de reciprocidad, que se apoya en la inversión de dos elementos: $A$ es a $B$ como $B$ es $a A ; b)$ el de transitividad, sintetizado en el principio Si a A es igual a By Bes igual a $C$, entonces, A es igual $a C$; $c$ ) el de incompatibilidad, que se asemeja al principio lógico de no contradicción; $d$ ) el de definición, que impone el modo cómo se quiere que se entienda un concepto y e) el de comparación, en el cual se contrasta dos realidades entre sí.

En cuanto a los argumentos basados en la estructura de lo real, estos establecen «una conexión entre las razones admitidas y otros que se intenta promover» (Perelman y Olbrechts-Tyteca, 1998, p. 402). Destacan el argumento pragmático, que pone en evidencia los efectos positivos o negativos que puede tomar la realización de un evento; y b) argumento de autoridad, que recurre a una autoridad o institución especializada como medio de prueba en apoyo de una opinión.

Las técnicas del tercer tipo fundan lo real a partir de dos mecanismos: a partir de un caso particular, y a través de la comparación de un caso cuya estructura se asemeja a otro más conocido. Así, se presentan $a$ ) el argumento por el ejemplo, que establece una regla general a partir de hechos particulares o ejemplos que permitan concretizar la idea abstracta o general; $b$ ) la analogía, que justifica una opinión a través de una situación, hecho o evento similar en su estructura, pero más familiar en su contenido, y c) el argumento por la ilustración, cuya función es reforzar la adhesión a una regla admitida, proporcionando casos particulares que esclarezcan el enunciado general.

\subsection{La estructura argumentativa}

Lo Cascio (1998), basándose en las ideas de (van Eemeren, Grootendorst y Snoeck, 2006) propone tres tipos de argumentación: simple, múltiple y arracimada. La argumentación simple está formada por una opinión (o) y un argumento (A): 
Figura 1. Esquema de la estructura argumentativa simple

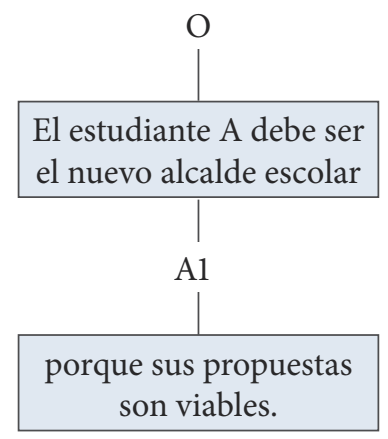

Elaborado a partir de Lo Cascio, 1998.

A diferencia de la argumentación múltiple, que está constituida por una opinión y uno o dos más argumentos coordinados entre ellos que se encuentran en un mismo nivel:

Figura 2. Esquema de la estructura argumentativa múltiple

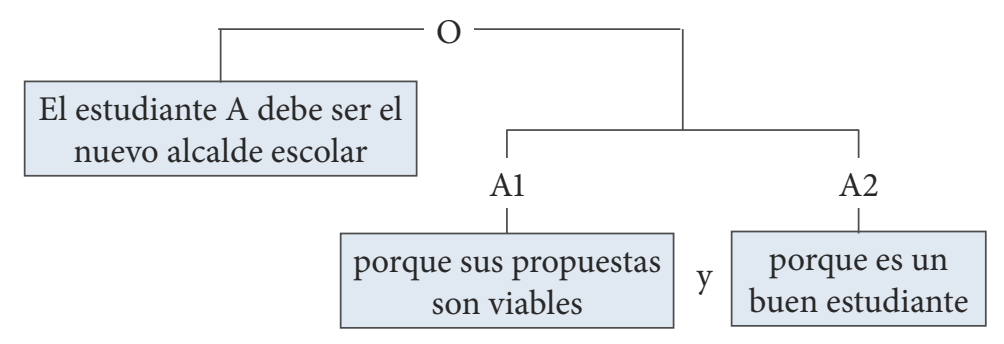

Elaborado a partir de Lo Cascio, 1998.

Por su parte, la argumentación arracimada está formada de una opinión y otros argumentos de apoyo que, a su vez, se convierten en otra opinión y dan origen a otros argumentos. Se muestra como un árbol ramificado que va de arriba a abajo:

72 Lengua \& Sociedad, vol. 18, n. ${ }^{\circ}$ 1, Lima, enero-junio de 2019 
La argumentación en la esfera escolar: análisis pragmalingüístico

Figura 3. Esquema de la estructura argumentativa arracimada

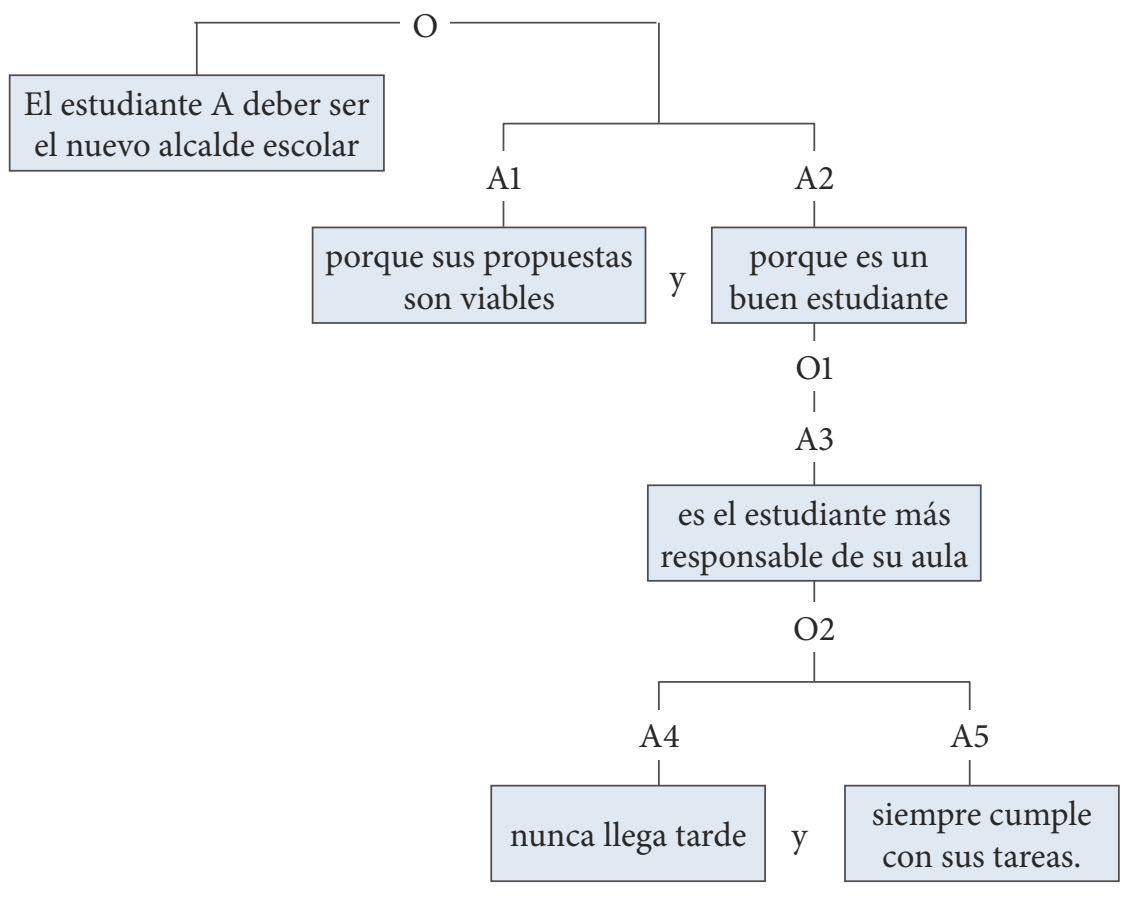

Elaborado a partir de Lo Cascio, 1998.

\subsubsection{La estructura de la argumentación: opinión,} argumento, regla general y reserva

Adicional a la opinión y al argumento, Lo Cascio (1998) propone el concepto de regla general $(\mathrm{RG})$ y reserva $(\mathrm{R})$. La regla general se define como las garantías que sostienen a los argumentos. Así, de la argumentación «iMafalda, obedéceme porque soy tu madre» se desprende la regla general: Las hijas deben obediencia a los padres.

En cuanto a la reserva - que Toulmin ya había desarrollado-, esta tiene la función de explicitar «dudas y posibles objeciones sobre la validez u oportunidad de la tesis» (Toulmin, 2007, p. 123). Así en el ejemplo propuesto por Toulmin "Harry es ciudadano británico, a menos que sus padres sean extranjeros o se haya naturalizado americano", la reserva expresa una duda sobre la nacionalidad de Harry. Tal como sostiene Lo Cascio (1998, p. 148): «La reserva tiene la función de indicar que, a partir del mismo dato utilizado para llegar a la opinión sostenida, 
puede llegarse, en la misma situación, a conclusiones diferentes aplicando reglas generales distintas».

A modo de ejemplo, un dato (la casa está a oscuras) podría llevarnos a conclusiones diferentes según la regla general en que se sostiene. Si se tiene la costumbre de apagar las luces cuando se sale de casa, entonces es probable que los dueños hayan salido; pero si la regla general fuese «se apaga las luces para que no entren los mosquitos», la conclusión no puede ser la antes señalada. La reserva, entonces, se anticipa a una objeción hipotética: «La casa está a oscuras, probablemente no hay nadie, a no ser que no quieran que entren mosquitos». Entonces la reserva se originará del mismo dato considerado para un argumento y presentará una conclusión alterna.

Desde otro ángulo del concepto aludido, la reserva se anticipa a las posibles objeciones de su auditorio u opositor, y a quien priva de un argumento que luego podría esgrimir: El conductor merece prisión preventiva porque acabó con la vida de dos personas, salvo que el conductor haya perdido el control de su automóvil por culpa de otro conductor. En la propuesta de Lo Cascio, la reserva tiene la jerarquía de un argumento, y debe ser analizada como tal.

Figura 4. Esquema de la estructura argumentativa y presencia de la reserva

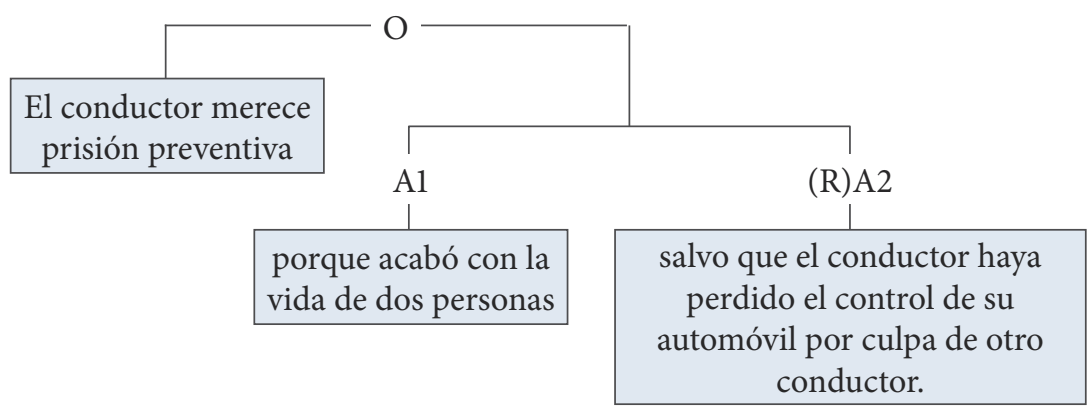

Elaborado a partir de Lo Cascio, 1998.

La opinión, el argumento y la regla general forman parte de la estructura mínima de la argumentación: ARG $=\mathrm{O}+\mathrm{RG}+\mathrm{A}$. A la combinación $\mathrm{RG}+\mathrm{A}$, Lo Cascio le da el nombre de Justificación (Js), de modo tal que la estructura sería:

74 Lengua \& Sociedad, vol. 18, n. ${ }^{\circ}$ 1, Lima, enero-junio de 2019 
La argumentación en la esfera escolar: análisis pragmalingüístico

Figura 5. Esquema básico de la estructura argumentativa

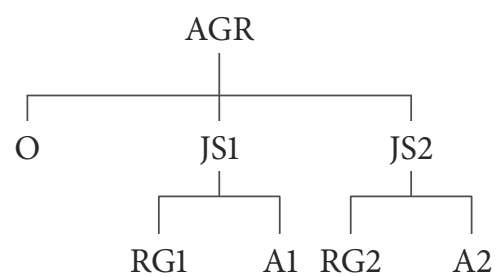

Fuente: Lo Cascio, 1998, p. 138.

No obstante, en la estructura arracimada, cada argumento puede ser también —en otra estructura inferior - una opinión por justificar, que también necesitará de su propia regla general y argumento:

Figura 6. Esquema representativo de los elementos de la argumentación

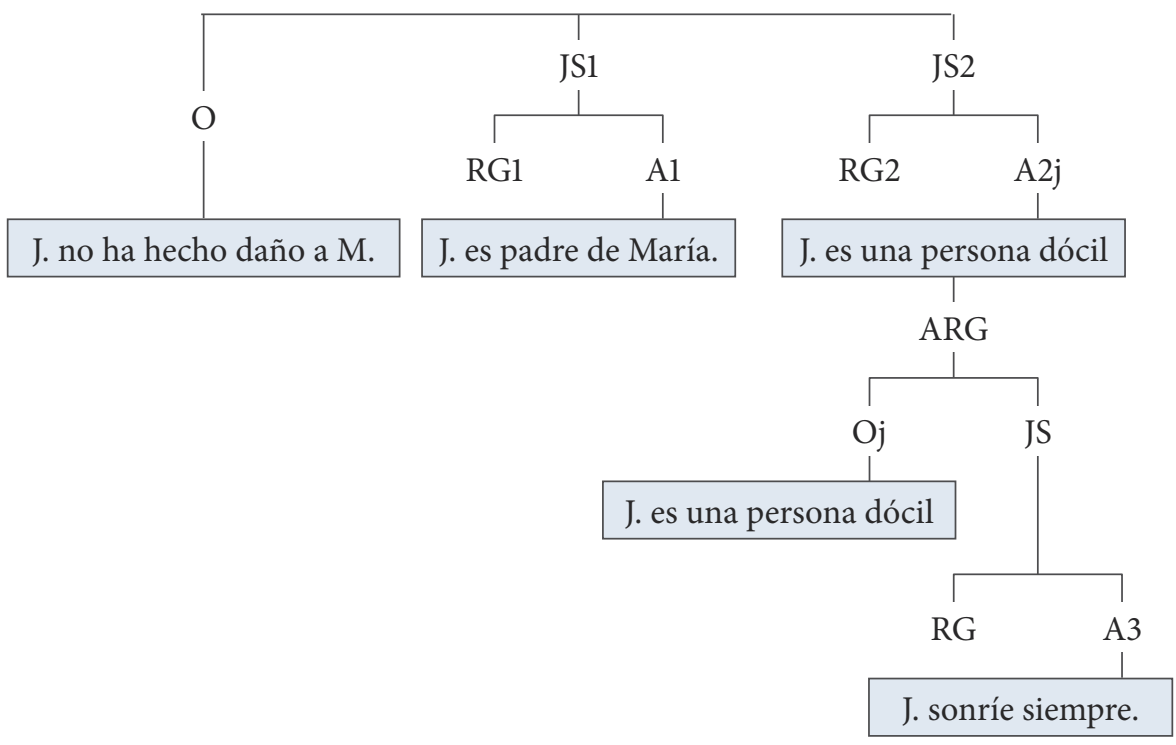

Fuente: Lo Cascio, 1998, p. 141.

Para indicar que dos enunciados comparten el mismo contenido, pero cumplen distintas funciones (argumento y opinión), se acompaña tanto al argumento (A) como a la opinión (o) el índice $j$. 


\subsection{La orientación argumentativa}

Un elemento clave en la argumentación - y en general, en todo acto comunicativo- son los marcadores, que Martín Zorraquino y Portolés (1999) definen como elementos que tiene la función de «guiar, de acuerdo con sus distintas propiedades morfosintácticas, semánticas y pragmáticas, las inferencias que se realizan en la comunicación» (p. 4057). Dichos autores clasifican los marcadores del discurso en cinco grupos: los estructuradores de la información, los reformuladores, los operadores argumentativos, los marcadores conversacionales y los conectores. Estos últimos - a su vez - se dividen en aditivos, consecutivos y contraargumentativos.

Por su parte, Domínguez (2007, p. 25) señala que «los argumentos de una relación argumentativa pueden estar coorientados, es decir, seguir una misma dirección argumentativa conducente a una misma conclusión; en ese caso, se presentan como conectores y operadores de adición; o pueden estar antiorientados, es decir, que se enfrenten entre sí»; asimismo, los conectores pueden presentar una relación de oposición o manifestar una conexión entre un argumento y una conclusión, por lo que se presentarán como conectores de causalidad. Para efectos de esta investigación sintetizamos ambos criterios de clasificación destacando los conectores argumentativos de Domínguez (2007) y los reformuladores y operadores argumentativos de Martín Zorraquino y Portolés (1999), que se muestra en la siguiente tabla:

Tabla 1. Conectores argumentativos, reformuladores y operadores argumentativos

\begin{tabular}{|c|c|c|}
\hline \multirow{5}{*}{$\begin{array}{l}\text { Conectores } \\
\text { argumentativos }\end{array}$} & De adición & $\begin{array}{l}\text { y, o, ni, es más, aún más, máxime/hasta, incluso, ni } \\
\text { (siquiera), además, encima, de hecho, sobre todo, } \\
\text { asimismo, etc. }\end{array}$ \\
\hline & De oposición & $\begin{array}{l}\text { pero, sin embargo, no obstante, ahora bien, aunque, a } \\
\text { pesar de todo/con todo, aun así, y eso que, eso sí, en } \\
\text { todo caso, en cambio, en cualquier caso, etc. }\end{array}$ \\
\hline & De causalidad & $\begin{array}{l}\text { porque, ya que, puesto que, dado que, (y) es que } \\
\text { al fin y al cabo, a fin de cuentas, etc. }\end{array}$ \\
\hline & De consecuencia & $\begin{array}{l}\text { por (lo) tanto, por consiguiente, luego, entonces, así } \\
\text { (es) que, así, así pues, pues, en/por consecuencia, de } \\
\text { modo/ manera que, etc. }\end{array}$ \\
\hline & De condición & $\begin{array}{l}\text { en caso contrario, de lo contrario, a no ser que, a menos } \\
\text { que, salvo que, excepto que }\end{array}$ \\
\hline
\end{tabular}

76 Lengua \& Sociedad, vol. 18, n. ${ }^{\circ}$ 1, Lima, enero-junio de 2019 
La argumentación en la esfera escolar: análisis pragmalingüístico

\begin{tabular}{l|l|l}
\hline & Explicativos & Es decir, o sea, esto es \\
\cline { 2 - 3 } Reformuladores & Rectificativos & Mejor dicho, mejor aún, más bien \\
\cline { 2 - 3 } & $\begin{array}{l}\text { De } \\
\text { distanciamiento }\end{array}$ & $\begin{array}{l}\text { En cualquier caso, en todo caso, } \\
\text { de todos modos, etc. }\end{array}$ \\
\hline Operadores & $\begin{array}{l}\text { Operadores } \\
\text { de refuerzo } \\
\text { argumentativo }\end{array}$ & En suma, en conclusión, etc. \\
\hline argumentativos & $\begin{array}{l}\text { Operadidares de } \\
\text { concreción }\end{array}$ & por ejemplo, en particular, etc. \\
\hline
\end{tabular}

Tabla elaborada a partir de los tipos de conectores, reformuladores y operadores argumentativos propuestos por Martín Zorraquino y Portolés (1999) y conectores argumentativos de Domínguez (2007).

\section{Metodología}

Los textos analizados en este trabajo son parte de una investigación más amplia de carácter cualitativo que analiza la configuración de la argumentación escrita de escolares que cursan el quinto grado de secundaria de una institución educativa pública ubicada en el distrito de Bellavista (Callao). En este estudio, participaron 60 alumnos, cuyas edades oscilan entre los 15 y 17 años, pertenecientes a dos de las ocho secciones del $5 .{ }^{\text {to }}$ año de secundaria y distribuidas en dos turnos (mañana y tarde). Treinta y dos alumnos asisten al turno mañana y veintiocho a la tarde. Se eligió a tres docentes del área de Comunicación para que estuvieran a cargo de la aplicación de la prueba, cuyo tiempo estimado fue de 45 minutos, aunque algunos de los estudiantes concluyeron antes del tiempo previsto. Se eligió tres textos a favor y tres en contra.

La unidad de análisis está conformada por textos argumentativos breves de estructura básica, es decir, solo se evalúa los argumentos que construyen los estudiantes para apoyar su postura. Los participantes son alumnos que provienen de distritos colindantes al distrito de Bellavista, como Carmen de la Legua Reynoso, La Perla y el cercado del Callao, cuyas familias son consideradas de clase mediabaja. El recojo de los casos a analizar se hizo a través de la aplicación de una prueba de desarrollo, un tipo de prueba escrita constituida por una pregunta abierta que 
permite al alumno elaborar su propia respuesta sin que esté sujeto a alguna estructura que la condicione. La elección de esta actividad reside, principalmente, en el interés de identificar las características pragmalingüísticas que configuran los argumentos utilizados por los estudiantes.

La prueba plantea la siguiente pregunta ¿Crees que es conveniente eliminar los exámenes de admisión para ingresar a las universidades públicas del país?, que se convierte en el tema en el cual manifestarán su postura y propondrán argumentos que lo justifiquen. Se eligió este tema a razón del interés generado por estudiantes que cursan el último año de la educación secundaria sobre las posibilidades que tienen de continuar su educación a nivel superior, una vez que egresen del colegio, ya sea en un instituto, CETPRO o universidad. Por lo general, tiene como primera intención el ingreso a una universidad y, dado que los participantes provienen de estratos económicos pertenecientes al nivel C (APEIM, 2016), el ingreso a una universidad privada resulta, en muchos casos, imposible de ser solventado por la familia, puesto que requiere el pago de pensiones a lo largo de cinco años como mínimo. Entonces, ingresar a una universidad pública se convierte en una posibilidad cercana a su realidad, pero exige al postulante demostrar el dominio de las competencias básicas cognitivas y el manejo de información precisa, a través de un examen de admisión, por lo que muchos egresados optan por estudiar en «academias preuniversitarias» y de este modo prepararse antes de rendir la prueba de admisión a la universidad.

\subsection{Procedimientos de obtención de información}

La aplicación de la prueba se realizó en diciembre del 2018 en la institución educativa pública Dora Mayer, ubicada en el distrito de Bellavista (Callao). Los docentes que aplicaron esta prueba laboran más de quince años en esta institución educativa y están a cargo del curso de Comunicación a nivel secundario, y trabajan con los estudiantes durante todo el año escolar. En ese sentido, no se evidenció inconvenientes para que la aplicación de prueba sea desarrollada por la totalidad de los estudiantes, ya que están habituados a la presencia de los maestros. Antes de la prueba, se estipuló que los profesores no intervinieran en la opinión de los alumnos, ni en sus argumentos; sin embargo, sí podían brindar información previa sobre el objetivo de la prueba. Durante el desarrollo, no se reportó algún inconveniente de orden cognitivo o conductual. Luego de recoger las pruebas desarrolladas, se procedió a seleccionar los textos que formarían parte del corpus. Se recolectó un

78 Lengua \& Sociedad, vol. 18, n. ${ }^{\circ}$ 1, Lima, enero-junio de 2019 
total de 60 textos, de los cuales solo seis fueron considerados como parte de este estudio. Finalmente, se procedió a iniciar el análisis de los textos escritos por los estudiantes, que se resume en los siguientes pasos:

a. Transcripción del texto argumentativo escrito por el estudiante.

b. Representación del tipo de estructura argumentativa que se crea a partir de la organización de los argumentos y los conectores argumentativos.

c. Reconocimiento de la quaestio (la cuestión), la presuposición del punto de vista y así como de la probatio y refutatio.

d. Identificación de los elementos que conforman la fuerza ilocucionaria del acto argumentativo: argumentos (A), las reservas (R) y los declarativos de uso (DU).

e. Identificación y clasificación de los conectores argumentativos coorientados, antiorientados y de conexión entre un argumento y una conclusión, y los reformuladores y operadores argumentativos.

f. Clasificación de las técnicas argumentativas según Perelman y OlbrechtsTyteca utilizadas por los escolares para apoyar su punto de vista.

\subsection{Procedimientos de análisis}

El procedimiento de análisis de la configuración de la argumentación escolar se enfocó en los siguientes aspectos:

a. La fuerza ilocucionaria, que permitió conocer si los enunciados expuestos son argumentos que justifican la postura del estudiante o solo tienen la función de ampliar, explicitar o explicar el argumento y si se trata de reservas que destacan las potenciales objeciones del interlocutor. Asimismo, facilitó la representación de la estructura argumentativa que elaboran los estudiantes.

b. La orientación argumentativa, que consistió en la identificación de los conectores argumentativos coorientados, antiorientados, de aquellos que indican una conexión entre un argumento y una conclusión, así como de los reformuladores y operadores argumentativos.

c. El soporte retórico, esto es, las técnicas argumentativas presentes en la argumentación escolar.

De acuerdo con la explicación dada, el procedimiento de análisis pragmalingüístico de la argumentación escolar se puede representar de la siguiente manera: 
Figura 7. Representación gráfica del modelo de análisis pragmalingüístico de la argumentación escolar

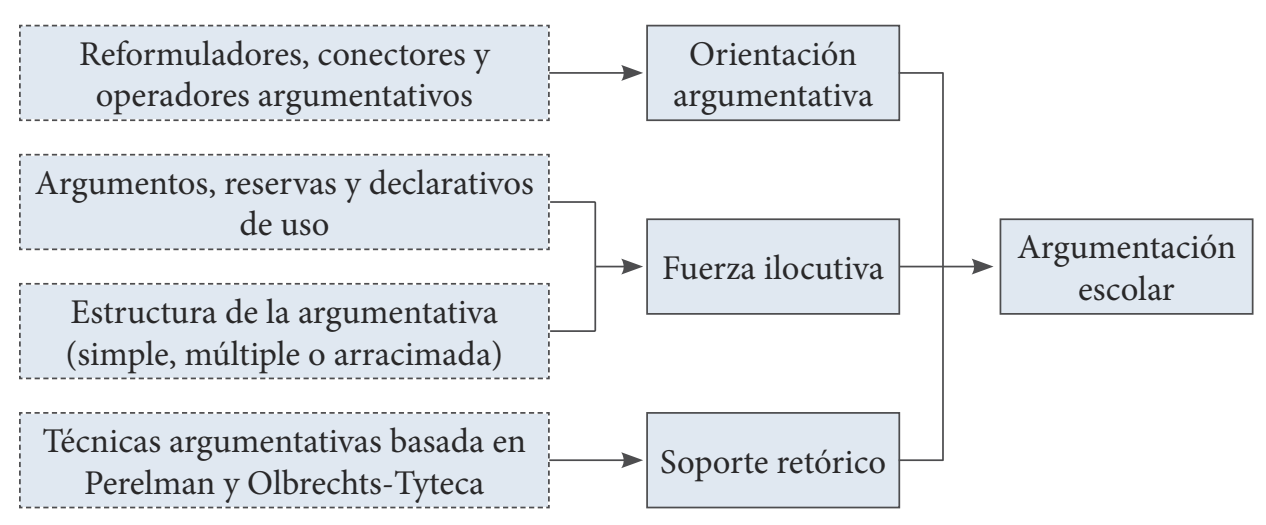

Fuente: Elaboración propia.

\section{Análisis del corpus seleccionado}

Quaestio: ¿Crees que es conveniente eliminar los exámenes de admisión para ingresar a las universidades públicas del país?

\subsection{Transcripción del texto}

No porque si se eliminan entraría cualquier tipo de gente y dejaríamos de lado a los que de verdad merecen esos cupos para estudiar; además el examen define el coeficiente intelectual del alumno para saber si pasa o no pasa a estudiar; ya que si un alumno entra sin dar el examen quizá no llegue a dar el cien por ciento y luego repita de ciclo y no avance; en cambio si entra uno y rindió bien el examen sería diferente, pero no todos los casos son así. Hay casos donde los más inteligentes no pasan y los que son estudiantes promedio pasan el examen; quizá eso pueda ser por el nerviosismo pero de todas formas un examen no define el acceso a una universidad o no define tu inteligencia, pero lo que define el examen es si estás preparado para una nueva etapa, y si pasas significa que estás preparado, mas no que llegue a ser fácil para la persona, así que los exámenes siempre tienen que darse y no eliminarlos, ya que eso le demuestra al estudiante lo que vendrá, y así estar preparado para lo que viene y si no das el examen pensará que es fácil pero en realidad no es así.

8o Lengua \& Sociedad, vol. 18, n. ${ }^{\circ}$ 1, Lima, enero-junio de 2019 


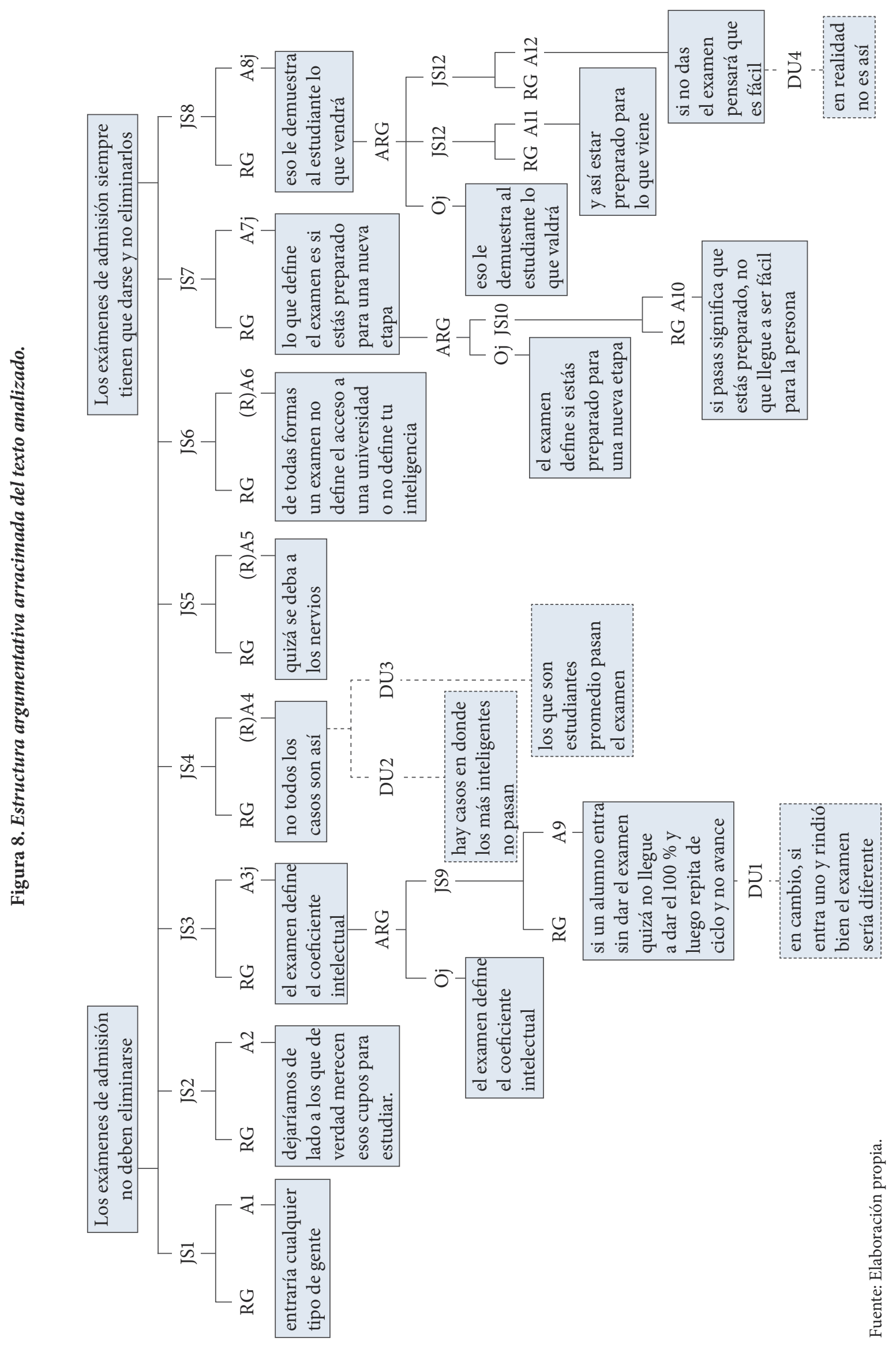




\subsection{El reconocimiento de la fuerza ilocucionaria del acto argumentativo y la orientación argumentativa}

En relación a la quaestio ¿Crees que es conveniente eliminar los exámenes de admisión para ingresar a las universidades públicas del país?, que presupone la conveniencia de seguir aplicando los exámenes de admisión, el estudiante considera que «no sería conveniente eliminar los exámenes de admisión», entonces estaría argumentando a favor de su aplicación, por lo que la estructura argumentativa de tipo arracimada sería un probatio (o confirmatio). Así, el argumento A1, introducido por el conector porque, advierte que «si se eliminan [los exámenes de admisión] entraría cualquier tipo de gente», el cual es apoyado por el argumento A2: «dejaríamos de lado a los que de verdad merecen esos cupos para estudiar» (que se vincula semánticamente a A1 a través del conector de adición $y$ ) y A3j: «el examen define el coeficiente intelectual del alumno para saber si pasa o no pasa a estudiar» (entiéndase si el postulante está o no capacitado intelectualmente para estudiar), que se une con el argumento anterior A2, mediante el conector de adición además. A su vez A3j justifica su argumento por medio del argumento A9 que predice que «si un alumno entra sin dar el examen quizá no llegue a dar el cien por ciento y luego repita de ciclo y no avance», situación hipotética que es apoyada con el declarativo de uso DU1 - introducido a través del conector de oposición en cambio- «si entra uno y rindió bien el examen sería diferente».

Sin embargo, a través del conector pero, el argumento A3j es puesto en duda por la reserva (R)A4: «No todos los casos son así», que es apoyado a través de los declarativos de uso coordinados DU2: «Hay casos donde los más inteligentes no pasan» y DU3: «los que son estudiantes promedio pasan el examen». No obstante, esta reserva ve atenuada su carácter refutativo por (R)A5: "quizá eso pueda ser por el nerviosismo», lo que le permite a A3j recuperar su fuerza argumentativa que el argumento contrario "No todos los casos son así» había menguado. De este modo, el emisor persiste en su idea de que los exámenes de admisión discriminan de manera eficiente la capacidad intelectual de los postulantes; si alguien inteligente no ingresó, esto se debería no a una deficiencia de los exámenes de admisión, sino a los nervios del postulante. Empero, A3j («el examen define el coeficiente intelectual del alumno para saber si pasa o no pasa a estudiar») ve reformulado su afirmación con el argumento A6: «de todas formas un examen no define el acceso a una universidad o no define tu inteligencia». Este nuevo argumento -aunque utilice el conector antiorientado pero no se puede considerar

82 Lengua \& Sociedad, vol. 18, n. ${ }^{\circ}$ 1, Lima, enero-junio de 2019 
una reserva, ya que la intención del estudiante es aclarar la real función que cumple el examen de admisión.

En vista que su argumento es reformulado, el proponente añade un nuevo argumento, antecedido por el conector pero, A7j: «lo que define el examen es si estás preparado para una nueva etapa», que precisa lo afirmado por A6, en un último esfuerzo por no abandonar del todo su inicial argumento A3j. Con este nuevo argumento, el estudiante no quiere desprenderse de la idea que el examen de admisión define «algo», ya no será el coeficiente intelectual del postulante, pero sí la suficiente preparación para pasar a una etapa más exigente. Este razonamiento (A7j) es apoyado por el argumento A10: «si pasas significa que estás preparado, no que llegue a ser fácil para la persona».

Posteriormente, el punto de vista es reiterado e introducido por un orientador de consecuencia: "así que los exámenes siempre tienen que darse y no eliminarlos», y justificado por a8j: «eso le demuestra al estudiante lo que vendrá» (probablemente, con este verbo el emisor se refiera no solo a los cursos que el postulante deba cursar en la vida universitaria, sino también la exigencia que esta supone), el cual, a su vez, es sostenido por los argumentos coordinados A11: "y así estar preparado para lo que viene», y el argumento A12: «si no das el examen pensará que es fácil» (de este modo el emisor intenta prevenir una extrapolación equivocada de parte del postulante: si ingresar no es difícil, tampoco lo será permanecer), que es apoyado por el declarativo de uso DU4, introducido por el conector restrictivo: "pero en realidad no es así», cuya +función es explicitar que no se debe pensar que el examen de admisión es fácil.

\subsection{El soporte retórico}

Dos técnicas argumentativas - de acuerdo a la clasificación de Perelman y Olbrechts-Tyteca (1989) - destacan en el texto analizado: el argumento pragmático y el de definición. Así, la eliminación de los exámenes de admisión ocasionaría graves consecuencias: que ingresen a estudiar tanto aquellos que no lo merecen como aquellos que mereciéndolo no lo hagan: porque si se eliminan entraría cualquier tipo de gente (A1) y dejaríamos de lado a los que de verdad merecen esos cupos para estudiar (A2). No obstante, las consecuencias no solo afectan a terceras personas, sino también al que pretende estudiar sin merecerlo, dado que este alumno probablemente no esté capacitado para rendir lo que se espera de un estudiante universitario y desapruebe los cursos: ya que si un alumno entra 
sin dar el examen quizá no llegue a dar el cien por ciento y luego repita de ciclo y no avance (A9).

Otra técnica a la que apela - como ya hemos señalado- es la de definición: $e l$ examen define el coeficiente intelectual del alumno para saber si pasa o no pasa a estudiar (A3j), definición que luego desiste: A6: de todas formas, un examen no define el acceso a una universidad o no define tu inteligencia. Empero, líneas después el emisor insiste en su estrategia de definición, aunque de manera más cautelosa: lo que define el examen es si estás preparado para una nueva etapa (A7j).

\section{Conclusiones}

El análisis de los textos realizados por un procedimiento cualitativo-descriptivo resulta ser un recurso pertinente para dar cuenta de las características pragmáticas, lingüísticas y retóricas que configura la argumentación de los escolares. Los resultados muestran que en el desarrollo argumentativo existe la presencia de reservas y declarativos de uso. Del mismo modo, se evidencia que las reservas no solo mitigan la fuerza ilocucionaria de un argumento, también de otras reservas.

Es frecuente que los estudiantes -en el desarrollo de su argumentaciónreformulen sus argumentos, en su propósito de ser claros y exactos con sus argumentos. Asimismo, se observa la repetición del punto de vista - con el que se inicia la argumentación - en el avance de la progresión argumentativa. Otro punto importante es el uso limitado que tienen los estudiantes de los conectores argumentativos. Los más recurrentes suelen ser $y$, además, o, pero, aunque, en cambio, porque, ya que y entonces, a los que se les atribuye valores pragmáticos y contextuales que, en muchos casos, tienen mayor peso significativo que el valor semántico que expresa. Las técnicas argumentativas utilizadas preferentemente por los escolares son el argumento pragmático y el de definición.

Nos encontramos con algunas limitaciones para que la estructura argumentativa sea representada tal y como lo proponen van Eemeren y Lo Cascio, pues los autores no consideran, en sus estructuras a los declarativos de uso, que a pesar de ser mencionado por van Eemeren y Grootendorst (2013) no es representado en ninguno de sus modelos propuestos, dejando de lado la posibilidad de considerar enunciados que no tienen como fin justificar una opinión. Creemos que este es un aspecto importante a tomar en cuenta en el análisis y representación de la argumentación.

84 Lengua \& Sociedad, vol. 18, n. ${ }^{\circ}$ 1, Lima, enero-junio de 2019 
La argumentación en la esfera escolar: análisis pragmalingüístico

\section{Referencias bibliográficas}

Albadalejo, T. (1993). Retórica. Madrid, España: Síntesis.

Apeim. Asociación Peruana de Empresas de Investigación de Mercados. (2016). Niveles socioeconómicos 2016. Disponible en: http://www.apeim.com.pe/wp-content/themes/apeim/docs/nse/apeim-nse-2016.pdf

Austin, J.L. (1982). Cómo hacer cosas con palabras. Barcelona, España: Paidos

Camps, A. \& Dolz, J. (1995). Enseñar a argumentar: un desafío para la escuela actual. CL \& E: Comunicación, lenguaje y educación, 25(1), 5-8. Disponible en: https://dialnet.unirioja.es/servlet/articulo?codigo $=2941554$

Domínguez, M. (2007). Conectores discursivos en textos argumentativos breves. Madrid: Arco Libros.

Eemeren, F. (2019). La teoría de la argumentación: Una perspectiva pragmadialéctica. Lima, Perú: Palestra.

Eemeren, F. \& Grootendorst, R. (2013). Los actos de habla en las discusiones argumentativas. Santiago de Chile: Ediciones Universidad Diego Portales.

Eemeren, F., Grootendorst. R. \& Snoeck, F. (2006). Argumentación: análisis, evaluación, presentación. Buenos Aires: Biblos.

García, K. \& Alarcón, Luisa (agosto de 2015). ¿Cómo conectan los jóvenes escolares sus ideas para argumentar? Análisis el uso de conectores en su discurso. Entreciencias: diálogos en la Sociedad del Conocimiento, 3(7), 253-262. Disponible en https://www.redalyc.org/articulo.oa?id $=4576 / 457644945010$

Lo Cascio, V. (1998). Gramática de la argumentación. Estrategias y estructuras. Madrid: Alianza Universidad.

Migdalek, M., Santibánez, C., Rosemberg, C. (2014). Estrategias argumentativas en niños pequeños: Un estudio a partir de las disputas durante el juego en contextos escolares. Revista signos. Estudios de lingüística, 47(86), 435-462. DOI: $10.4067 /$ So718-0934201400030000 5

Perelman, Ch. (1998). El imperio retórico. Retórica y argumentación. Colombia: Norma.

Perelman, Ch. \& Olbrechts-Tyteca, L. (1989). Tratado de la argumentación. La nueva retórica. Madrid: Gredos.

Searle, J. (1994). Actos de habla. Ensayo de filosofía del lenguaje. Buenos Aires: Planeta-Agostini.

Toulmin, S. (2007). Los usos de la argumentación. Barcelona, España: Península. Zorraquino, M. \& Portolés, L. (1999). Los marcadores del discurso. En I. Bosque \& V. Demonte (Eds.), Gramática descriptiva de la lengua española (pp. 40514213). Madrid: Espasa Calpe. 